under discussion. The presence of a pneumomediastinum could have interfered with filling of the right heart, but the successful outcome of conservative treatment indicated that this accumulation of air was a minor problem. The fall in blood pressure was considered to be unrelated to the giving of promazine 8 hours before. McNicholl (1960) pointed out that a lateral chest radiograph shows the amount of air in the mediastinum. This radiograph would have been of assistance in this case.

\section{Summary}

A young woman developed a subcutaneous emphysema of the chest wall during an attack of status asthmaticus. She was seriously ill but responded to conservative treatment alone. The method of production of this complication and its effects have been discussed.
The writer is indebted to Dr. F. A. Richards fe helpful criticism.

\section{REFERENCES}

MaCklin, C. C. (1937): Pneumothorax with Massi年 Collapse from Experimental Local Over Inflation of the Lung Substance, Canad. med. Ass. J. 36, 414.

MCNiCHOLl, B. (1960): Pneumomediastinum an Subcutaneous Emphysema in Status Asthmaticus Requiring Surgical Decompression, Arch. Dis. Childth 35, 389.

Payne, T. W. and Geppert, L. J. (1961): Mediastinä and Subcutaneous Emphysema Complicating Bronchiat Asthma in a Nine-year-old Male. J. Allergy, 32, 13द्2 SCHRIRE, T. and SCHRIRE, X. (1952) : Surgic영 Emphysema in Asthma, S. Afr. med. J., 26, 465.

\title{
SPONTANEOUS RUPTURE OF THE SPLENIC ARTERY IN EARLY PREGNANCY
}

\author{
I. G. WyLIE, M.B., B.S. \\ Surgical Registrar, Royal Sussex County Hospital, Brighton 7.*
}

SPONTANEOUS rupture of the splenic artery is a rare complication of pregnancy though its occurrence has been more frequently recorded in recent years. The following case is presented out of interest primarily because of its unusual occurrence in the early stages of pregnancy and because its successful treatment adds a further maternal survivor in a condition which has always carried a heavy mortality.

\section{Case Report}

Miss S. age 19, was admitted as an emergency to Hove General Hospital on September 1st, 1964, at 5.45 p.m. The patient's condition did not allow a detailed history to be obtained, but it was known that she had collapsed 45 minutes before admission and on regaining consciousness, complained of severe colicky pain in the left lower quadrant of the abdomen. Her last menstrual period was at the end of May.

The patient was desperately collapsed and on the verge of unconsciousness. Neither the radial pulse nor the blood pressure could be recorded and the extremities were cyanosed. There were signs of a previous pregnancy.

The abdomen was soft on palpation, but tenderness was elicited in the left flank. No masses were felt. Bowel sounds were absent. Vaginal examination revealed a boggy swelling in the Pouch of Douglas and showed the absence of vaginal bleeding. The uterus was enlarged to the size of a ten-weeks pregnancy and the fornices were acutely tender.

A provisional diagnosis was made of ruptured ectopic pregnancy probably, having regard to the extended period of gestation, interstitial in position.

*Present address: Department of Anatomy, London Hospital, Medical School, London, E.1.
Immediate attention was turned to resuscitation Oxygen was administered by mask and transfusiom commenced with plasma followed by a pint of uE matched O-positive blood which was the only bloged available. The patient responded well to these measuros and by the time arrangements had been completed fô operation, the patient's blood pressure was recorded 90/60 mm Hg.

Operation (J.C.F.L.W.) Commenced 7.45 p.m. The abdomen was opened through a left lower paramediang incision. The peritoneal cavity contained four pints of fresh blood; this was evacuated and the patients condition deteriorated, her blood pressure falling barely recordable levels. The uterus was enlarged pregnancy to a size estimated as being compatible with a 14 week cyesis. Both ovaries and tubes were normá. Normal pelvic findings recalled the possibility of 9 ruptured splenic artery aneurysm and the upper abdomen was examined after extending the incision. A small regt was found in the splenic artery just proximal to the hilum. No aneurysmal dilatation of the vessel wis noted. The spleen appeared normal in size and appea ance. The splenic vessels were clamped and haemorrhage having been controlled, splenectomy was performed?. The patient's condition began to improve following arrest of haemorrhage. During operation the patien received by transfusion, two pints of plasma and two pints of cross-matched blood. A further three pints cross-matched blood were given in the next 12 hours.

Histology. The section of the spleen itself shows obvious abnormality. Sections of the splenic artey show considerable variation in calibre from one part of the wall and there is quite clear evidence of cystic media necrosis in the thicker areas. This diagnosis is confirmed by a special stain for elastic tissue.

Progress. The following day the patient felt wet 
though there was a small amount of vaginal bleeding. She had a satisfactory urinary output. Going back over the history, the patient stated she had previously been in good health. Returning to work from the cloakroom after micturition she had a sudden attack of dizziness. She tried to stand up hoping to obtain a drink of water, but had fainted. She regained consciousness for a few minutes and then fainted again. On waking she experienced severe colicky left-sided abdominal pain which radiated to the left groin and she vomited once. She could recall no more until her admission to hospital. The only interest in her past medical history was that she had a full-term normal delivery of a child two years earlier after an uneventful pregnancy.

On the second post-operative day the patient had a complete abortion with minimal blood loss. Her further post-operative course was uneventful.

\section{Discussion}

Spontaneous haemorrhage from intra-abdominal vessels is rare, but well documented cases have been recorded as affecting most of the arteries and many of the veins. The splenic artery appears particularly vulnerable in this respect, the rupture being often associated with macroscopic aneurysmal dilatation of the vessel. All collective reviews have shown an appreciable proportion of cases occur during pregnancy. In the case of splenic artery aneurysm $25 \%$ of females affected were pregnant (Owens and Coffey 1953).

The first maternal survivor was not reported until 1940 (MacLeod and Maurice 1940). As far as I can trace, this is the 48th recorded case associated with pregnancy and the 10th maternal survivor. To date there have been no foetal survivors.

Of those cases which have been associated with pregnancy, $60 \%$ ruptured in the third trimester of pregnancy or the early puerperium and the other $40 \%$ in the second trimester. Only one other case has been reported as occurring so early in pregnancy (Wiessenborn, 1936) and this case, in addition, was associated with a ruptured spleen. The increased intra-abdominal pressure and hyperkinetic circulation associated with the later stages of pregnancy are the usual aetiological factors suggested to explain this association.

At such an early stage of pregnancy as this occurred these factors do not apply and it seems that the lesion in the artery wall may be of sufficient severity to cause its spontaneous rupture.

Although the mortality of the condition has dropped since the more general availability of blood for transfusion, it still remains high. An important consequence of the frequent occurrence of rupture of the vessel near to term is that the uterus has to be emptied by Caesarean section before the splenic area can be reached - this delay may be sufficient to cause the death of the patient.

\section{Summary}

A case of spontaneous rupture of the splenic artery in pregnancy is reported. Attention is drawn to the fact that this complication may occur in early pregnancy.

I am indebted to Mr. J. C. F. Lloyd Williamson for his kindness in allowing me to publish this case, to Dr. J. H. Crawford, who administered the anaesthetic, and to Dr. R. I. K. Elliott for his pathological report.

\section{REFERENCES}

OWens, J. C. and COFFEY, R. J. (1953): Collective Review; Aneurysms of Splenic Artery Including Report of 6 Additional Cases, Surg. gynec. Obst., 97, 313.

MAClEOD, D. and MAURICE, T. (1940): Rupture of Branch of Splenic Artery Associated with Pregnancy, Lancet, i, 924.

WIESSENBORN, W. (1936): Weber Mitzgefaessrupturen, Chirug., 8, 883. 